\title{
Pesquisa de Clostridium perfringens em carnes bovinas embaladas a vácuo comercializadas no Distrito Federal e entorno
}

\section{Clostridium perfingens research on vacuum packed beef commercialized on Distrito Federal and in the surrounding area}

\author{
Igor de Oliveira Poty ${ }^{1}$, Joana Marchesini Palma², Francisco Carlos Faria Lobato ${ }^{3}$, Ana Lourdes \\ Arrais de Alencar $\mathrm{Mota}^{4}$, Angela Patricia Santana ${ }^{5}$
}

\begin{abstract}
Resumo
O objetivo deste trabalho foi detectar a presença de Clostridium perfringens em 54 amostras de carne bovina embaladas a vácuo comercializadas na região do Distrito Federal, bem como detectar a presença da toxina cpe por PCR, ainda avaliar os meios de cultivo ágar SPS ${ }^{\circledR}$ e ágar TSC $®$, com e sem etapa de pré-enriquecimento das amostras em caldo infusão de cérebro e coração (BHI) na câmara de anaerobiose, e posterior incubação das placas de SPS ${ }^{\circledR}$ e TSC ${ }^{\circledR}$ tanto em jarra de anaerobiose, como em câmara de anaerobiose. Na análise da incubação das placas em ágar SPS ${ }^{\circledR}$ e TSC $®$, sem a etapa de préenriquecimento em caldo BHI na câmara de anaerobiose, observou-se o crescimento em apenas uma $(1,85 \%)$ das 54 amostras analisadas, em ambos os meios de cultivo e formas de incubação. Com a etapa de pré-enriquecimento com caldo BHI em câmara de anaerobiose, observou-se crescimento em todas as 54 amostras (100\%), em ambos os meios de cultivo e formas de incubação. Na reação em cadeia de polimerase (PCR) nenhuma das cepas oriundas das amostras analisadas apresentaram a amplificação de fragmento do gene da toxina cpe. Os resultados evidenciam a presença de C. perfringens em carnes embaladas a vácuo comercializadas no Distrito Federal e Entorno, porém não foi detectada a toxina cpe em nenhuma cepa isolada analisada. Na comparação estatística aplicando o teste qui-quadrado de McNemar, observou-se que houve diferença significativa $(p<0,001)$ entre as análises sem e com a etapa de pré-enriquecimento em caldo BHI, verificando-se a influencia positiva do meio na recuperação de esporos, destacando desta forma a importância do enriquecimento prévio em meio BHI e a incubação em câmara de anaerobiose, na recuperação de esporos deste microrganismo.
\end{abstract}

Palavras chave: Câmara de anaerobiose. Toxina CPE. Clostridiose alimentar. Toxinfecção alimentar. Agar SPS. Agar TSC

\begin{abstract}
The aim of this work was to detect Clostridium perfringens in 54 samples of vacuum packed beef sold at the Federal District area, and to detect the presence of the cpe toxin gene by Polymerase chain reaction (PCR), also evaluate the culture medium SPS ${ }^{\circledR}$ agar and TSC ${ }^{\circledR}$ agar, with and without pre-enrichment step of the samples in Brain Heart Infusion (BHI) broth in the anaerobic chamber, and to promote the incubation of the plates in anaerobic jar and anaerobic chamber. The results of the incubation on SPS ${ }^{\circledR}$ agar and TSC $®$ agar, without the pre-enrichment step in BHI, growth was observed in only one $(1,85 \%)$ of the 54 analyzed samples, in both culture media and incubation methods. With the pre-enrichment step with BHI broth in the anaerobic chamber, growth was observed in all 54 samples (100\%), in both

\footnotetext{
Mestrando em Saúde Animal pela Universidade de Brasília, Distrito Federal, Brasil. Laboratório de Microbiologia dos Alimentos, Faculdade de Agronomia e Medicina Veterinária, Instituto de Ciências Central Sul, Campus Darcy Ribeiro, Universidade de Brasília, Distrito Federal, Brasil.

${ }^{2}$ Doutoranda em Saúde Animal pela Universidade de Brasília, Distrito Federal, Brasil. Laboratório de Microbiologia dos Alimentos, Faculdade de Agronomia e Medicina Veterinária, Instituto de Ciências Central Sul, Campus Darcy Ribeiro, Universidade de Brasília, Distrito Federal, Brasil.

${ }^{3}$ Doutoranda em Ciência Animal pela Escola de Veterinária da UFMG - Escola de Medicina Veterinária da UFMG, Avenida Antônio Carlos, 6627, Belo Horizonte, MG, 31.270-901, Brasil.

${ }^{4}$ Médica Veterinária responsável técnica do laboratório de Epidemiologia Veterinária e Doutoranda em Saúde Animal pela Universidade de Brasília - Faculdade de Agronomia e Medicina Veterinária, Instituto de Ciências Central Sul, Campus Darcy Ribeiro, Universidade de Brasília, Distrito Federal, Brasil.

${ }_{5}^{5}$ Doutorado em Ciências Biológicas (Biologia Molecular) pela Universidade de Brasília, Distrito Federal, Brasil. Laboratório de Microbiologia dos Alimentos, Faculdade de Agronomia e Medicina Veterinária, Instituto de Ciências Central Sul, Campus Darcy Ribeiro, Universidade de Brasília, Distrito Federal, Brasil. E-mail: patvet@ unb.br
} 
culture media and incubation methods. At the PCR, In the polymerase chain reaction (PCR), none of the strains from the analyzed samples showed fragment amplification of the toxin cpe gene. The results showed the presence of $C$. perfringens in vacuum packed beef samples commercialized at the Distrito Federal area and surroundings, however the cpe toxin was not detected in any isolated strain analyzed. In the statistical test using the McNemar chi-square test, a significant difference $(p<0,001)$ was observed between the analysis with and without pre-enrichment step in BHI broth, verifying the positive influence of the medium in spore recovery, therefore to enhance the importance of the pre-enrichment stage in BHI broth and the incubation in anaerobic chamber in spore recovery for this microorganism.

Keywords: Anaerobic chamber. CPE toxin. Foodborne clostridiosis. Foodborne intoxication. Agar SPS. Agar TSC.

\section{Introdução}

O Clostridium perfringens é um bacilo anaeróbio, esporulante e faz parte da microbiota normal do trato gastrointestinal e urinário de humanos e animais, sendo também encontrado nas águas de rios e no solo. ${ }^{(1,2)}$ Tanto em humanos quanto em animais, $C$. perfringens provoca infecções e doenças histotóxicas originárias no intestino, como enterites e enterotoxemias. ${ }^{(3-4)}$ Este microrganismo provoca doenças tanto pela produção de toxinas, quanto pela invasão de tecidos, tendo como porta de entrada a ingestão de alimentos contaminados, lesões de pele e inalação. As toxinas podem ser produzidas no próprio organismo após a infecção ou são ingeridas pré-formadas. ${ }^{(5)}$

C. perfringens é classificado em 5 tipos toxigênicos de A a E, dependendo da toxina produzida. Além das 4 principais toxinas produzidas (alfa, beta, épsilon e iota), existem outras 17 toxinas que podem ou não estar associadas a quadros clínicos em humanos e em animais. Dentre as toxinas, a enterotoxina (cpe) tem papel confirmado nos casos de toxinfecção alimentar causada pelo mesmo. ${ }^{(6)}$

O cultivo desta bactéria em jarra de anaerobiose, com a passivação do cobre como meio gerador de anaerobiose é um método clássico e utilizado até hoje no Brasil e em diversas partes do mundo. Porém, dentre os métodos de cultivos de anaeróbios, o uso da câmara de anaerobiose se mostra a mais eficiente, pois propicia a capacidade de visualizar as colônias sem retirá-las da anaerobiose. A câmara é formada por um gabinete de plástico com luvas seladas a ele. Dentro do gabinete há uma mistura especial de gases contendo $85 \%{ }_{\mathrm{N} 2}, 10 \% \mathrm{CO}_{2}, 5 \% \mathrm{H}_{2}$, porém também podem ser encontradas misturas contendo $95 \% \mathrm{~N}_{2}$ e $5 \% \mathrm{H}_{2}{ }^{(7)}$. Dessa maneira, é possível garantir que a atmosfera dentro da câmara seja completamente anaeróbia.

Para o diagnóstico de $C$. perfringens em carnes e derivados, é possível utilizar o caldo e o ágar
BHI (Brain Heart Infusion), cuja função é induzir a germinação de esporos, sendo utilizado por diversos pesquisadores. ${ }^{(8-10)} \mathrm{O}$ caldo $\mathrm{BHI}$ tem sido utilizado no diagnóstico de clostridioses em animais, devido a sua eficiência na germinação de esporos. ${ }^{(11-13)}$ Os meios de cultivo mais usados para o isolamento de $C$. perfringens são o ágar Sulfito Polimixina Sulfadiazina (SPS) e o ágar Triptose Sulfito Cicloserina (TSC). ${ }^{(14)}$

De acordo com a Agência Nacional de Vigilância Sanitária, a toxinfecção alimentar por $C$. perfringens é a sexta mais frequente no Brasil, entretanto, deve-se notar que em $51,34 \%$ de todos os casos de toxinfecção alimentar o agente causador é ignorado. ${ }^{(15)}$ Nos Estados Unidos e no Canadá, a toxinfecção alimentar por $C$. perfringens é uma das mais comumente diagnosticadas. ${ }^{(16,17)} \mathrm{O}$ microrganismo já foi isolado a partir produtos derivados de carne bovina em diversos países como Jordânia, Costa do Marfim, Turquia, Estados Unidos e Holanda. ${ }^{(18-21)}$ Além do isolamento microbiológico, o diagnóstico molecular de $C$. perfringens a partir da toxina cpe vem sendo largamente usada por diversos pesquisadores tendo em vista a existência de diferenças na virulência entre as cepas..$^{(8,22-23)}$

Levando-se em consideração a importância da pesquisa desse microrganismo em carnes, as especificidades de seu cultivo, a relevância da toxina cpe em surtos de toxinfecção alimentar, ainda a ausência de pesquisas deste microrganismo em alimentos no Distrito Federal e entorno e os escassos trabalhos no Brasil, esse trabalho teve por objetivos avaliar a presença de $C$. perfringens em carnes bovinas embaladas a vácuo, comercializadas na região do Distrito Federal e entorno, fazendo a comparação entre o cultivo deste microrganismo em jarra de anaerobiose, utilizando a passivação do cobre como método de geração de anaerobiose, e o cultivo em câmara de anaerobiose com mistura de gases contendo $85 \% \mathrm{~N}_{2}, 10 \% \mathrm{CO}_{2}$ e $5 \% \mathrm{H}_{2}$, bem como os meios de cultivo ágar SPS e ágar TSC, e avaliar a influência da 
incubação das amostras com caldo BHI e detectar a presença do gene da toxina cpe nas cepas isoladas por reação em cadeia da polimerase (PCR).

\section{Material e Método}

\section{Origem das amostras}

Foram adquiridas 54 amostras de carne bovina resfriada embalada a vácuo, de marcas diversas, provenientes das regiões administrativas do Distrito Federal e entorno, entre os períodos de 01 de maio e 15 dezembro de 2014. As amostras foram adquiridas simulando uma situação real de compra pelo consumidor, em que uma unidade amostral era caracterizada por uma peça de carne embalada a vácuo, sem sinal de violação, dentro do prazo de validade e inspecionada pelo Serviço de Inspeção Federal (SIF) ou pelo Departamento de Inspeção de Produtos de Origem Vegetal e Animal do Distrito Federal (DIPOVA-DF). As amostras foram transportadas ao Laboratório de Microbiologia de Alimentos da UnB (LAMAL-UnB) em caixas isotérmicas, sendo acondicionadas sob refrigeração até o momento do processamento.

As metodologias para isolamento de C. perfringens utilizadas foram os protocolos ${ }^{(14,21)}$ e a Instrução normativa número 62 do Ministério da Agricultura, Pecuária e Abastecimento, de 2003. ${ }^{(24)}$. Foram retirados fragmentos de $25 \mathrm{~g}$, de cada unidade amostral, bem como colhidos e armazenados $1,0 \mathrm{~mL}$ de exsudato de carne presentes no interior da embalagem.

Isolamento de $\mathrm{C}$. perfringens a partir de $25 \mathrm{~g}$ de amostra de carne bovina

Antes da abertura das embalagens, as amostras foram higienizadas com álcool etílico $70 \%$, sendo em seguida coletados $1,0 \mathrm{~mL}$ de exsudato da carne para realização do enriquecimento em caldo BHI. Todas as alíquotas foram armazenadas em freezer da marca Continenta $l^{\circledR}$ sob a temperatura de $-10^{\circ} \mathrm{C}$. Foi utilizado a cepa $C$. perfringens ATCC $13124^{\circledR}$ como controle positivo para o isolamento microbiológico. O controle positivo para a cepa de $C$. perfringens cpe-positiva foi gentilmente cedida pelo Laboratório de Bacteriose e Pesquisa da Escola de Veterinária da Universidade Federal de Minas Gerais.

Em seguida, pesou-se $25 \mathrm{~g}$ de cada amostra em sacos esterilizados para homogeneização de amostras BagLight $^{\circledR}$, sendo em seguida adicionados 225 $\mathrm{mL}$ de água peptonada tamponada $1 \%$, formando então a diluição 1:10. A partir dessa diluição foram preparadas duas placas de petri utilizando o método de "pourplate", com uma placa contendo Agar TSC ${ }^{\circledR}$ (triptose, extrato de carne, digestão papaica de farinha de soja, extrato de levedura, metabisulfito de sódio, citrato férrico de amônio, D-cicloserina, Agar) e outra contendo Agar SPS ${ }^{\circledR}$ (caseína enzimática hidrolisada, sulfito de sódio, citrato férrico, extrato de levedura, sulfadiazinha, sulfato de polimixina B, Agar). Também foram preparadas mais duas placas usando "spread plate", com os mesmos meios de cultivos TSC e SPS.

As placas foram incubadas de dois modos distintos. As placas preparadas em "pourplate" foram acomodadas em jarra de anaerobiose da marca Permution ${ }^{\circledR} 36^{\circ} \mathrm{C}$, por 24 a 48 horas, tendo como método de geração de anaerobiose a passivação do cobre, ${ }^{(14)} \mathrm{e}$ pela IN62/2003. As demais placas em "spread plate" foram acomodadas em câmara de anaerobiose do tipo Forma Anaerobic Systems ${ }^{\circledR}$ da ThermoScientific ${ }^{\circledR}$ com mistura especial de gases contendo $85 \% \mathrm{~N}_{2}, 10 \%$ $\mathrm{CO}_{2}, 5 \% \mathrm{H}_{2}$, sob a mesma temperatura e tempo.

Isolamento de $\mathrm{C}$. perfringens a partir de exsudato de carne pré-enriquecido em caldo BHI.

Foi inoculado $1 \mathrm{~mL}$ do volume coletado no processamento inicial em $9 \mathrm{~mL}$ de caldo BHI, para cada amostra de carne bovina analisada. Sendo incubado em câmara de anaerobiose a $36^{\circ} \mathrm{C}$ por 24 a 48 horas..$^{(21)}$

Após esse período de pré-enriquecimento, o caldo inoculado foi utilizado para preparar 2 placas "pourplate", e 2 "spread plate" como descrito no processamento anterior. As placas em "pourplate" continham ágar SPS ${ }^{\circledR}$ e TSC ${ }^{\circledR}$ inoculou-se em cada uma delas a alíquota de $1 \mathrm{~mL}$ de caldo $\mathrm{BHI}$, em seguida foram incubadas em jarra de anaerobiose a $36^{\circ} \mathrm{C}$, por 24 a 48 horas, tendo como método de geração de anaerobiose a passivação do cobre. As placas em "spread plate" continham os mesmos meios de cultivo, e nelas inoculou-se uma alçada, contendo aproximadamente $5 \mu \mathrm{L}$ do caldo BHI e foram acondicionadas em câmara de anaerobiose sob a mesma temperatura e quantidade de tempo.

Foi considerado crescimento positivo o aparecimento de colônias negras e redondas características de $C$. perfringens, como descrito no manual do ágar TSC ${ }^{\circledR}$ e ágar SPS ${ }^{\circledR}$. Essas colônias foram submetidas à coloração de Gram para a observação dos bastonetes gram-positivos característicos da bactéria. 


\section{Análises estatísticas}

Para a verificação da ocorrência de $C$. perfringens em amostras de carne bovinas comercializadas no Distrito Federal e a comparação do crescimento entre os ágar $\mathrm{TSC}^{\circledR}$ e ágar SPS ${ }^{\circledR}$, a análise estatística empregada foi a de um estudo observacional. ${ }^{(25)}$ Para a análise da influência do pré-enriquecimento com o caldo BHI e a incubação em câmara de anaerobiose, utilizou-se o teste do qui-quadrado de McNemar ${ }^{(26)}$, tendo em vista o pareamento das amostras.

\section{Detecção do gene da toxina CPE por reação em cadeia da polimerase (PCR)}

Para a realização do PCR para a detecção do gene da toxina cpe, seguiu-se o protocolo proposto por Kaneko et al. ${ }^{(8)}$ Todas as cepas que apresentaram crescimento característico de colônias negras e redondas, características de $C$. perfringens foram submetidas à PCR. Para a reação foram utilizados os primers cpe-F3 (5' ACA TCTGCAGATAGCTTAGGAAT3') ecpe-B3 (5' CCAGTAGCTGTAATTG TTAAGTGT 3'). ${ }^{\text {(27) }}$

O método de extração de DNA utilizado foi o do fenol, clorofórmio e álcool isoamílico. ${ }^{(28)} \mathrm{A}$ amplificação foi realizada em termociclador da marca MyCycler ${ }^{\mathrm{TM}}$ ThermalCycler $^{\circledR}$, com um ciclo inicial de $94^{\circ} \mathrm{C}$ por 2 minutos, seguido por 35 ciclos a $94^{\circ} \mathrm{C}$ por 30 segundos, $55^{\circ} \mathrm{C}$ por 30 segundos e $68^{\circ} \mathrm{C}$ por 30 segundos, e uma extensão final de $68^{\circ} \mathrm{C}$ por 8 minutos. Após a amplificação, os produtos da PCR foram analisados em gel de agarose $1,5 \%$, com concentração de $5 \mu \mathrm{g} / \mathrm{mL}$ de brometo de etídio, esperando-se encontrar produtos com 248 pares de bases.

\section{Resultados e Discussão}

\section{Isolamento de $\mathrm{C}$. perfrnigens a partir de 25 gramas de amostra de carne bovina}

Das 54 amostras analisadas em Agar TSC ${ }^{\circledR}$ e Agar SPS $^{\circledR}$, e incubadas tanto em jarra de anaerobiose quanto em câmara de anaerobiose, em apenas uma (01) amostra observou-se crescimento em ambos os meios de cultivo e em ambos os métodos de incubação. Nas demais amostras não foram observados nenhum crescimento. Obtendo-se desta forma a ocorrência de $1,85 \%$ (Tabela 1 ).
Tabela 1 - Pesquisa de Clostridium perfringens em 54 amostras de carnes bovina, sem etapa de préenriquecimento prévio em caldo BHI, com incubação em jarra de anaerobiose e câmara de anaerobiose, em meio de cultivos ágar SPS e ágar TSC

\begin{tabular}{lcc}
$\begin{array}{l}\text { Pesquisa de } \\
\begin{array}{l}\text { Clostridium } \\
\text { perfringes }\end{array}\end{array}$ & Agar SPS & Agar TSC \\
\hline $\begin{array}{l}\text { Incubação em jarra de } \\
\text { anaerobiose }\end{array}$ & $1 / 54(1,85 \%)$ & $1 / 54(1,85 \%)$ \\
$\begin{array}{l}\text { Incubação em câmara } \\
\text { de anaerobiose }\end{array}$ & $1 / 54(1,85 \%)$ & $1 / 54(1,85 \%)$ \\
\hline
\end{tabular}

Tavares e Serafini(23) encontraram C. perfringens em apenas $2 \%$ do total de 100 amostras de hambúrgueres de carne bovina, comercializados no município de Goiânia. Estes autores utilizaram o método de incubação em jarra de anaerobiose, sendo similares aos resultados observados neste estudo, em semelhantes condições. França Filho et al.(29) avaliaram a presença de $\mathrm{C}$. perfringens em meias-carcaças bovinas provenientes de abatedouros do Estado de Goiás. Em seu estudo não foi observado crescimento de $C$. perfringens em nenhuma das amostras analisadas, divergindo dos resultados obtidos neste estudo. Apesar de não se tratar de matriz da mesma espécie, os resultados deste trabalho também se diferenciaram dos obtidos por Kouassi et al.(20), que pesquisaram $C$. perfringens em 395 cortes de carne de aves na Costa do Marfin e evidenciaram a presença deste microrganismo em $5,06 \%$ das amostras. Huang(19) avaliou os efeitos do cozimento na ativação de esporos, e isolou $C$. perfringens a partir de amostras de carne previamente inoculadas com o microrganismo, utilizando ágar TSC como meio cultivo e fazendo incubação em câmara de anaerobiose, de tal maneira que observou crescimento desta bactéria em todas as amostras preparadas, sendo desta forma similar à este trabalho, no que se refere à utilização do meio de cultivo e forma de incubação.

Apesar do resultado ser de pesquisa de $C$. perfringens em carne fresca, em que não há padrões de presença ou ausência e nem de quantificação na RDC 12/ 2001 da Agencia Nacional de Vigilância Sanitária para este tipo de alimento, ainda de não se enquadrar nas características descritas por Silva et al.(14) no que se refere ao alimento ser capas de causar surtos com contagens superiores à $105 / \mathrm{g}$, não se pode descartar 
o risco para a saúde pública no caso de uma mal preparação deste alimento e uma possível exposição ao consumo humano.

\section{Isolamento de $\mathrm{C}$. perfringens a partir de exsudato de carne pré-enriquecido com caldo BHI.}

Foram observados crescimentos bacterianos característicos em todas as amostras preparadas em placas de petri contendo Agar SPS ${ }^{\circledR}$ e Agar TSC $®$, incubadas tanto em jarra de anaerobiose quanto em câmara de anaerobiose $(85 \% \mathrm{~N} 2,10 \% \mathrm{CO} 2,5 \% \mathrm{H} 2)$, perfazendo um total de $100 \%$ (Tabela 2), não sendo, desta forma, observadas nenhuma diferença entre os meios de cultivo e ao método de incubação.

Tabela 2 - Pesquisa de Clostridium perfringens em 54 amostras de exsudato de carne bovina, com etapa de préenriquecimento prévio em caldo BHI, com incubação em jarra de anaerobiose e câmara de anaerobiose, em meios de cultivos ágar SPS e ágar TSC

Pesquisa de
Clostridium perfringens $\quad$ Agar SPS Agar TSC
$\begin{aligned} & \text { Incubação em jarra de } \\ & \text { anaerobiose }\end{aligned}$
$54 / 54(100 \%)$
$54 / 54(100 \%)$

Incubação em câmara de anaerobiose

$54 / 54(100 \%) \quad 54 / 54(100 \%)$

Diversos autores obtiveram resultados positivos ao utilizarem o caldo BHI como meio de préenriquecimento para recuperação de esporos de $C$. perfringens. $^{(8,10,21)}$ Xiao et al. ${ }^{(21)}$ utilizaram o BHI para induzir a germinação de esporos de cepas C. perfringens isoladas de 98 alimentos diversos provenientes da inspeção sanitária da Holanda. Neste estudo os autores observaram a recuperação de esporos em todas as amostras, semelhante aos resultados obtidos neste trabalho, com a matriz carne bovina. Kaneko et al. ${ }^{(8)}$ em sua pesquisa sobre detecção de $C$. perfringens enterotoxigênico em amostras de carne bovina no Japão, utilizaram o enriquecimento prévio em BHI para realizar contagem de células bacterianas viáveis, e como nesse estudo, observaram a eficiência da recuperação de esporos deste microganismo em suas amostras. O mesmo foi observado por Wen e Macclane, ${ }^{(10)}$ que utilizaram o ágar BHI incubado em jarra de anaerobiose para recuperação de esporos de $C$. perfringens, em alimentos não envolvidos em surtos de toxinfecção alimentar, observando crescimento característico desta bactéria em 290 do total de 900 amostras.

Estes resultados corroboram com os obtidos neste estudo, em que a eficiência de se promover a etapa do pré-enriquecimento em caldo BHI é demonstrada. Em todos os trabalhos, os autores se mostram unânimes quanto à eficiência do caldo BHI na germinação de esporos de C. perfringens. Destaca-se a importância da câmara de anaerobiose, que possibilitou a realização da etapa de pré-enriquecimento em condições ideais de anaerobiose e segurança, sem as quais não seria possível sua realização. Entretanto, há que se ressaltar o alto custo para a implantação e manutenção deste equipamento, bem como os seus insumos. ${ }^{(7)}$

Não há, no Brasil, metodologia oficial que estabeleça o uso do caldo BHI para recuperação de esporos de C. perfringens tanto em câmara de anaerobiose quanto em jarra de anaerobiose. $\mathrm{O}$ cultivo de esporos de C. perfringens em meio líquido apresentou, neste trabalho, resultado satisfatório, e uma possível justificativa é a maior disponibilidade de nutrientes em meio líquido, que favorece a recuperação de cepas, que antes estariam inviáveis para o cultivo em meio sólido. ${ }^{(30)}$ Vale ressaltar que não foi realizada neste estudo a etapa de pré-enriquecimento em tubos contendo caldo BHI em jarra de anaerobiose, portanto são necessários mais estudos com o intuito de avaliar a viabilidade do processo de incubação do caldo BHI em jarra de anaerobiose, considerando que este é um método clássico e eficiente de se gerar atmosfera anaeróbia. ${ }^{(7)}$

$\mathrm{Na}$ análise estatística através do teste do quiquadrado de McNemar, observou-se diferença significativa $(p<0,001)$ entre o cultivo sem préenriquecimento e com pré-enriquecimento, comprovando que o meio BHI teve efeitos positivos na recuperação de esporos de $C$. perfringens.

Não foi encontrado nenhum estudo comparando o crescimento entre cepas de Clostridium perfringens, com e sem etapa de pré-enriquecimento em caldo BHI, inoculação em ágar SPS e ágar TSC com fase de incubação em jarra de anaerobiose e câmara de anaerobiose. No entanto, no trabalho Summanen et al. $^{(31)}$ foi comparado o crescimento de 54 cepas bactérias anaeróbias em ágar Brucella e a recuperação de bactérias anaeróbias a partir de 31 espécimes clínicos em ágar Brucella reduzido e ágar BEE, utilizando três 
métodos distintos de geração de anaerobiose: uma Anoxomat $^{\circledR}$, um sistema de GasPak $^{\circledR}$ e uma câmara de anaerobiose. Apesar de não ter sido observada diferença significativa no crescimento e recuperação de bactérias anaeróbias entre os três métodos de geração de anaerobiose, os resultados do estudo sugerem que o sistema Anoxomat ${ }^{\circledR}$ foi o mais eficiente entre três métodos comparados, por sua capacidade de gerar uma atmosfera anaeróbia satisfatória e ocupar pouco espaço físico. Similarmente, neste estudo não foi observada diferença significativa $(\mathrm{P}<0,001)$ entre $\mathrm{o}$ uso da jarra de anaerobiose com passivação de cobre e da câmara de anaerobiose no crescimento de $C$. perfringens.

\section{Detecção do gene da toxina $C P E$ por reação em cadeia da polimerase (PCR).}

Todas as cepas provenientes do cultivo das 54 amostras de carne bovina cultivadas em ágar SPS ${ }^{\circledR}$ e $\mathrm{TSC}^{\circledR}$, incubadas tanto em jarra de anaerobiose, quanto em câmara de anaerobiose, que demonstraram crescimento característico de $C$. perfringens, obtidas com e sem o pré-enriquecimento em caldo BHI, foram submetidas à detecção da toxina cpe por PCR, perfazendo, portanto, um total de 110 reações. Desse total, nenhuma apresentou amplificação para a presença da toxina, que indicaria a produção de enterotoxina responsável por intoxicação alimentar. Semelhante a este trabalho, Ferreira et al. ${ }^{(32)}$ ao realizarem tipagem molecular de cepas de $C$. perfringens, oriundas de abatedouros de suínos do Estado de São Paulo também não encontraram nenhuma amostra positiva para o gene cpe. Gomes et al. ${ }^{(33)}$ não encontraram amostras positivas para a toxinacpe em 171cepas oriundas de amostras de carne de frangos de corte, provenientes do Estado de Minas Gerais. Entretanto, Lahti et al. ${ }^{(34)}$ ao trabalhar com $C$. perfringens isolados a partir de alimentos comprovadamente envolvidos em surtos de toxinfecção alimentar, observou que $91 \%$ do seu total de 53 amostras apresentavam a toxina cpe, detectadas por PCR.

Apesar de nenhuma das cepas isoladas não possuírem o gene produtor da toxina cpe, não se pode afirmar que ele esteja ausente na região do Distrito Federal e Entorno, tendo em vista o número de amostras analisadas neste estudo. Maiores estudos devem ser conduzidos para se verificar a real presença deste microrganismo, bem como a detecção da toxina cpe.

\section{Conclusão}

Foi verificada a presença de $C$. perfringens em amostras de carne bovina embaladas a vácuo, comercializadas na região do Distrito Federal e entorno, no entanto nenhuma cepa isolada neste estudo apresentou a toxina cpe, pelo método de detecção por PCR. Também não foi observada diferença entre os meios de cultivos ágar SPS e ágar TSC. Destacase a recuperação de esporos de $C$. perfringens em caldo BHI, o qual foi significativamente diferente, demonstrando a eficácia do meio de cultivo, com incubação em câmara de anaerobiose, evidenciando a presença de esporos viáveis nas carnes bovinas, embaladas a vácuo. São necessários mais estudos com número maior de amostras para se avaliar a real situação sanitária, no que se refere à presença desta bactéria, bem como avaliar a presença da toxina cpe, em carnes embaladas a vácuo comercializadas no Distrito Federal e Entorno.

\section{Referencias}

1 Shindo Y, Dobashi Y, Sakai T, Monma C, Miyatani $\mathrm{H}$, Yoshida Y. Epidemiological and pathobiological profiles of Clostridium perfringens infections: review of consecutive series of 33 cases over a 13-year period. Int J Clin Exp Pathol. 2015 Jan 1;8(1):569-77.

2 Desmarais TR, Solo-Gabriele HM, Palmer CJ. Influence of soil on fecal indicator organisms in a tidally influenced subtropical environment. Appl Environ Microbiol. 2002 Mar;68(3):1165-72.

3 Chen J, Ma M, Uzal FA, McClane BA. Host cellinduced signaling causes Clostridium perfringens to upregulate production of toxins important for intestinal infections. Gut Microbes. 2014 JanFeb;5(1):96-107. doi: 10.4161/gmic.26419.

4 Li J, McClane BA. The sialidases of clostridium perfringens type D strain CN3718 differ in their properties and sensitivities to inhibitors. Appl Environ Microbiol. 2014 Mar;80(5):1701-9. doi: 10.1128/ AEM.03440-13. 
5 Lobato FC, Lima CG, Assis RA, Pires PS, Silva RO, Salvarani FM, et al. Potency against enterotoxemia of a recombinant Clostridium perfringens type $\mathrm{D}$ epsilon toxoid in ruminants. Vaccine. $2010 \mathrm{Aug}$;28(38):61257. doi: 10.1016/j.vaccine.2010.07.046

6 Pires PSP, Silva ROS, Lobato FCF. Clostridiose alimentar: clostridium perfringens. [Internet]. 2011 [citado 2015 jun 8]. Disponível em: http:// www.zoonoses.org.br/absoluto/midia/imagens/ zoonoses/arquivos_1330097103/3829_clostridiose alimentar_c_perfringens.pdf

7 Jousimies-Somer H, Wadsworth KTL. Anaerobic bacteriology manual. 6th. ed. Rio de Janeiro: Starpub; 2002.

8 Kaneko I, Miyamoto K, Mimura K, Yumine N, Utsunomiya $\mathrm{H}$, Akimoto $\mathrm{S}$, et al. Detection of enterotoxigenic Clostridium perfringens in meat samples by using molecular methods. Appl Environ Microbiol. 2011 Nov;77(21):7526-7532. doi: 10.1128/AEM.06216-11.

9 Akhtar S, Paredes-Sabja D, Torres JÁ, Sarker MR. Strategy to inactivate Clostridium perfringens spores in meat products. Food Microbiol. 2009 May;26(3):272-7. doi: 10.1016/j.fm.2008.12.011.

10 Wen Q, MacClane BA. Detection of enterotoxigenic Clostridium perfringens type A isolates in american retail foods. Appl Environ Microbiol. 2004 May;70(5):2685-91.

11 Paredes-Sabja D, Carker MR. Host serum factor triggers germination of Clostridium perfringens spores lacking the cortex hydrolysis machinery. J Med Microbiol. 2011 Dec;60(Pt 12):1734-41. doi: 10.1099/jmm.0.031575-0.

12 Goldstein MR, Kruth AS, Bersenas AM, Holowaychuk MK, Weese JS. Detection and characterization of C. perfringens in the feces of healthy and diarrheic dogs. Can J Vet Res. 2012 Jul;76(3):161-5.

13 Fernandez-Miyakawa ME, Marcellino R, Uzal FA. Clostridium perfringens type A toxin production in 3 commonly used culture media. J Vet Diagn Invest. 2007 Mar;19(2):184-6.

14 Silva N, Junqueira VCA, Silveira NFA, Santos RFS, Gomes RAR. Manual de métodos de análise microbiológica de alimentos e água. 4th. ed. São Paulo: Varela; 2010.
15 Ministério Da Saúde (BR). Vigilância epidemiológica das doenças transmitidas por alimentos - VE-DTA. [Internet]. 2014 [citado 2015 jun 18]. Disponível em: http://www.anrbrasil.org.br/new/pdfs/2014/3 PAINEL_1_ApresentacaoRejaneAlvesVigilanciaEpi demiologica-VE-DTA-Agosto_2014_PDF.pdf

16 Centers for Disease Control and Prevention. Clostridium perfringens. Food borne safety. [Internet]. 2014 [cited 2015 Jun 22]. Available from: http://www. cdc.gov/foodsafety/clostridium-perfingens.html

17 Public Health Agency of Canada. Clostridium perfringens. Pathogens safety data sheet. [Internet]. [cited 2015 Jun 21]. Available from: http://www. phac-aspc.gc.ca/lab-bio/res/psds-ftss/clostridiumperfringens-eng.php

18 Al-Qadirii H, Sablani SS, Ovissipour M, Al-Alami N, Govindan B, Rasco B. Effect of oxygen stress on growth and survival of Clostridium perfringens, Campylobacter jejuni, and Listeria monocytogenes under different storage conditions. J Food Prot. 2015 Apr;78(4):691-7. doi: 10.4315/0362-028X.JFP-14427.

19 Huang L. Dynamic determination of kinetic parameters, computer simulation, and probabilistic analysis of growth of Clostridium perfringens in cooked beef during cooling. Int $\mathrm{J}$ Food Microbiol. 2015 Feb 16;195:20-9. doi: 10.1016/j. ijfoodmicro.2014.11.025

20 Kouassi KA, Dadie AT, N'Guessan KF, Dje KM, Loukou YG. Clostridium perfringens and Clostridium difficile in cooked beef sold in Côte d'Ivoire and their antimicrobial susceptibility. Anaerobe. 2014 Aug;28:90-4. doi: 10.1016/j.anaerobe.2014.05.012.

21 Xiao Y, Wagendorp A, Moezelaar R, Abee T, Wells-Bennik MH. A wide variety of Clostridium perfringens Type A food-borne isolates that carry a chromosomal CPE gene belong to one multilocus sequence typing cluster. Appl Environ Microbiol. 2012 Oct;78(19):7060-8. doi: 10.1128/AEM.0148612.

22 Erol I, Goncuoglu M, Ayaz ND, Bilir Ormanci FS, Hildebrandt G. Molecular typing of Clostridium perfringens isolated from turkey meat by multiplex PCR. Lett Appl Microbiol. 2008 Jul;47(1):31-4. doi: 10.1111/j.1472-765X.2008.02379.x. 
23 Tavares TM, Serafini AB. Avaliação microbiológica de hambúrgueres de carne bovina comercializados em sanduicherias tipo trailers em Goiania-GO. Rev. Patol. Trop. 2003 jan-jun;32(1):45-52.

24 Ministério da Agricultura Pecuária e Abastecimento (BR). Instrução normativa número 62. Brasília; 2003.

25 Pereira MG. Epidemiologia: teoria e prática. Rio de Janeiro: Guanabara-koogan; 1995.

26 Petrie A, Watson P. Estatística em ciência animal e veterinária. 2.. ed. São Paulo: Rocca; 2009.

27 Miki Y, Miyamoto K, Kaneko-Hirano I, Fujiuchi $\mathrm{K}$, Akimoto S. Prevalence and characterization of enterotoxin gene-carrying Clostridium perfringens isolates from retail meat products in Japan. Appl Environ Microbiol. 2008 Sep;74(17):5366-72. doi: 10.1128/AEM.00783-08

28 Russel DW, Sambrook J. The condensed protocols from molecular cloning: a laboratory manual. New York: Cold Spring Harbor; 2006.

29 França Filho AT, Mesquita AJM, Oliveira JP, Bueno CP, Lopes JH, Couto M.V, et al. Qualidade bacteriológica de meias-carcaças bovinas oriundas de matadouros-frigoríficos do estado de Goiás habilitados para exportação. Cienc. Anim. Bras. 2006;7(3):315-5.

30 Sula L, Sundaresan TK. WHO co-operative studies on a simple culture technique for the isolation of mycobacteria. 2. Comparison of the efficacy of lyophilized liquid medium with that of loewensteinjensen (1-j) medium. Bull World Health Organ. 1963;29:607-25.

31 Summanen PH, McTeague M, Väisänen ML, Strong CA, Finegold SM. Comparison of recovery of anaerobic bacteria using the Anoxomat, anaerobic chamber, and GasPak jar systems. Anaerobe. 1999 Feb;5(1):5-9.

32 Ferreira TSP, Moreno AM, Almeida RR, Gomes CR, Gobbi DDS, Filsner PH, et al. Molecular typing of Clostridium perfringens isolated from swine in slaughterhouses from São Paulo State, Brazil. Ciênc. Rural. 2002 ago;42(8):1450-56.

33 Gomes AM, Lobato FCF, Martins NRS, Assis RA. Genotipicação de Clostridium perfringens isolados de frangos de corte através da PCR múltipla. Ciênc. Rural. 2008;38(7):1943-1947.
34 Lahti P, Heikinheimo A, Johansson T, Korkeala H. Clostridium perfringens type A strains carrying a plasmid-borne enterotoxin gene (genotype IS1151cpe or IS1470-like-cpe) as a common cause of food poisoning. J Clin Microbiol. 2008 Jan;46(1):371-3.
Recebido em: 25 maio 2017

Aceito em: 28 nov. 2017 